\title{
Silicone Intubation in External Dacryocystorhinostomy
}

\author{
Anila Monka ${ }^{1}$, Sulejman Zhungli ${ }^{2}$ \\ ${ }^{1}$ University Hospital Centre "Mother Theresa" Tirana, Albania
}

\begin{abstract}
External dacryocystorhinostomy (DCR) is the gold standard surgical technique for the treatment of nasolacrimal duct obstruction (1). Since its introduction by Gibbs in 1967, intubation with silicone tubes has been widely used in lacrimal duct surgery. A total 87 patients who had DCR surgery between 2013 and 2014 were retrospectively reviewed in University Hospital Centre "Mother Theresa" in Tirana, Albania which is a tertiary referral hospital. All patients had primary nasolacrimal duct obstruction and no previous surgery for nasolacrimal duct obstruction. A complete ophthalmologic examination was performed.The aim of the study was to assess the rate of success of silicone tube intubation as compared to patients that this method was not used.. Success rate were 89\% $(47 / 53)$ in silicone group, and $71 \%(20 / 34)$ in silicone free group with a statistically significant difference (p=0.04).External DCR with silicone intubation is safe and effectivesurgery in patients whom we expect less favorable outcome. The complications associated with silicone intubation are negligible.
\end{abstract}

Keywords: external dacryocystorhinostomy, silicon tube, surgery

\section{Introduction}

External dacryocystorhinostomy (DCR) is the gold standard surgical technique for the treatment of nasolacrimal duct obstruction (1). Since its introduction by Gibbs in 1967, intubation with silicone tubes has been widely used in lacrimal duct surgery (2). However, effect of silicone intubation on patency of lacrimal system during external DCR in cases of primary nasolacrimal duct obstruction (NLDO), canalicular obstruction or in revision surgeries is still controversial.We do not perform, in our facility, silicone intubation in primary NLDO except in cases with intraoperative complications such as iatrogenic canalicular trauma or flap rupture. There are only a few reports on beneficial effect of silicone intubation on the success rates. On the other hand, more reports demonstrated no significant difference between the success rates of routine external DCR irrespective of silicone intubation (3). Freng et al. performed a meta-analysis based on a literature search and they did not find any benefit for silicone intubation in primary DCR (4).Silicone tube may cause some complications such as canalicular or punctal slitting, and granuloma formation in the nose and lacrimal fossa $(5,6)$. Kim et al. concluded that prolonged silicone intubation is related with Pseudomonas aeruginosa infections and final surgical failure (7).In our institution, intubation is performed in revision surgeries and in cases with canalicular problems. We believe that a silicone tube only acts, in a way, as a guide for the canalicular epithelium to progress farther when there is its discontinuity, without adhering to other tissues. Moreover, it ensures patency during the healing process. We evaluated the outcome of silicone intubation in external DCR patients with distal canalicular or common canalicular obstructions and we concluded that silicone intubation is indicated in patients with canalicular problems (8). Boboridis et al. reported a success rate of $92 \%$ after external DCR with membranectomy and this ratio is comparable with the outcome of routine DCR procedures (9).Silicone intubation has some functional and mechanical effects on epiphora. Silicone tube itself may have a mechanical obstructive effect on the canalicular system. However, silicone intubation enhances lacrimal pump function by supporting punctal position and apposition during blinking. Silicone intubation also increases lacrimal tear drainage via increasing capillarity. Kim et al. (10) reported that silicone intubation decreases epiphora in patients after anatomically successful but functionally unsuccessful DCR surgeries.Silicone intubation increases cost and prolongs postoperative followup periods of the patients. Based on current medical evidences and our experience, silicone intubation is mainly indicated in DCR surgery in selected cases of distal or common canalicular obstructions and routine intubation can be avoided in cases with primary NLDO. The aim of the study was to assess the rate of success of silicone tube intubation as compared to patients that this method was not used.

\section{Materials and Methods}

A total 87 patients who had DCR surgery between 2013and 2014 were retrospectively reviewed in University Hospital Centre "Mother Theresa" in Tirana, Albania which is a tertiary referral hospital. All patients had primary nasolacrimal duct obstruction and no previous surgery for nasolacrimal duct obstruction. A complete ophthalmologic examination was performed. The patency of lacrimal drainage system was evaluated with lacrimal syringing. All patients were examined by otorhinolaryngology department and when needed assessed with computed tomography. Informed consent was taken from all patients.

Age, gender, laterality, andlacrimal irrigation in the third month visit were recorded. Surgical success was accepted as the patency of the formed ostium with lacrimal syringing/irrigation. All cases were done by a single surgeon (AG). Exclusion criteria were canalicular stenosis, epiphora due to adnexal, corneal, conjunctival diseases, and age less than 20 years of age.Descriptive methods and independent $t$ test were used for statistical analyses and a $\mathrm{p}$ value $<0.05$ wasaccepted as significant. 


\section{International Journal of Science and Research (IJSR) \\ ISSN (Online): 2319-7064 \\ Index Copernicus Value (2013): 6.14 | Impact Factor (2014): 5.611}

\section{Results and Discussion}

Silicone tube intubation was added to surgery in 53 consecutive patients and was not used in 34 patients. The mean age were 61.4 years (range, 32-82) in patients in whom silicone tube was used, and 53.4years (range, 23-75) in patients that was not used (fig. 1). Female to male ratio were 29/24 and in silicone tube group, and 29/5 in silicone free group.Twenty one $(40 \%)$ out of 53 patients in silicone group was operated from right side, and also 21 (62) out of 34 patients in silicone free group was operated from the right side.Success rate were $89 \%(47 / 53)$ in silicone group, and $71 \%(20 / 34)$ in silicone free group with a statistically significant deifference $(\mathrm{p}=0.04)$ (fig. 2). There were no case with distal or common canalicularobstruction.In silicone group, no punctal erosion, corneal erosion, and granuloma formation were seen for following 6 months in postoperative period. In only one patient, silicone road extrusion was seen and the patient was managed with the aiding of an intranasal endoscope, and the silicone road was retrieved to previous position.Silicone intubation simultaneous with DCR was first described by Gibbs (5). Silicone tube is placed almost routinely during endonasal DCR (6). On the other hand, routine use of silicone tubes at the time of external DCR is controversial (11). Silicone intubation is generally indicated for canalicular obstruction and the conditions in which excessive postoperative scarring might occur. Various sets and methods have been described for lacrimal intubation (911). In these sets, silicone tubes are attached to metal probes ranging in length from $45 \mathrm{~mm}$ to $177 \mathrm{~mm}$. In this method, the metal probe passes from the canaliculi first and the silicone tube follows it. To place the tube, it is necessary to pass the whole probe from the canalicular segment and to retrieve it from the rhinostomy site. Uneasy manipulation of the metal probes, the difficulty in retrieving the probe from the wound and the nose, possible canalicular trauma, and relative expense are the main disadvantages of this method. Although curved and shorter metal probes are proposed, the difficulties in retrieving the probes have not yet been overcome (15). Various researchers have suggested a different intubation method for external DCR surgery. In this method, a lacrimal probe (Bowman No. 1 probe, 0.90 $\mathrm{mm}$ in diameter) is used for passing the tubes through the canaliculus. The outer diameter of the silicone tubes is 0.94 $\mathrm{mm}$. Oblique incisions are made $3 \mathrm{~mm}$ away from the ends of the tubes. The lacrimal probe is inserted into this incision and advanced about $2 \mathrm{~mm}$. The probe with the tube is inserted into the punctum, advanced through the canaliculus, and pulled out from the cavity of the sac. The disadvantages of this technique include the difficulty in adjusting the length of vertical incision on the tube, inserting the metal probe into the incision, and breaking of the fragile part at the end of the tube. In addition, it may be difficult to pass the lacrimal probe attached to the silicone tube through the relatively narrower canaliculus. In our technique, the silicone tube is advanced in front of an introducer, i.e. a lacrimal canula. The canula that we used was $0.45 \mathrm{~mm}$ in diameter. It can be easily inserted into the silicone tube, and forms a relatively tight connection. Enlargement of the lacrimal punctum with one snip facilitates both the entrance of the silicone tube and postoperative lacrimal irrigation. During lacrimal intubation, the metal probes may easily cause canalicular injury. To avoid this complication, the tubes should be advanced gently according to the trace of the canaliculus. Nasolacrimal canal obstruction may induce marked changes in the anatomical course of the common canaliculus particularly in patients with the enlarged lacrimal sacs (17). The curved and light lacrimal canula easily accords the trace of the canaliculi and does not lead to any distortion. In our opinion, straight and heavier metal probes are more likely to cause canalicular distortion.

\section{Conclusions}

External DCR with silicone intubation is safe and effective surgery in patients whom we expect less favourable outcome. The complications associated with silicone intubation are negligible. There is no statistically significant difference in outcome between presac and post sac obstruction. No significant difference in the outcome between patients with and without a history of previous surgery. There is a tendency for the symptoms to recur after tube removal. We recommend a longer follow up with more number of patients to evaluate its long time results.

\section{References}

[1] Pandya VB1, Lee S, Benger R, Danks JJ, Kourt G, Martin PA, Lertsumitkul S, McCluskey P, Ghabrial R. External dacryocystorrrhinostomy:assessing factors that influence outcome. Orbit. 2010 Oct;29(5):291-7. PMID: 20958176

[2] Feng YF, CAi JQ, Zhang JY, Han XH. A meta-analysis of primary dacryocystorhinostomy with and without silicone intubation. Can J Ophthalmol. 2011 Dec;46(6):521-7. PMID: 22153640

[3] Kim SE, Lee SJ, Lee SY. Clinical significance of microbial growth on the surface of silicone tubes removed from dacrocystorhinostomy patients. Am J Ophthalmol. 2012 Feb;153(2):253-257.e1. PMID: 21920491

[4] Buttanrı IB, Serin D, Karslıŏlu S, Akbaba M, Fazıl K, Acar B, Sevim MS . The outcome of silicone intubation and tube removal in external dacryocystorhinostomy patients with distal canalicular obstruction. Eur J Ophthalmol. 2012 Feb 27;22(6):878-881. PMID: 22388775

[5] Boboridis GK, Bunce C, Rose GE. Outcome of external dacryocystorhinostomy combined with membranectomy of a distal canalicular obstruction. Am J Ophthalmol. 2005 Jun;139(6):1051-5. PMID: 15953435

[6] Kim NJ, Kim JH, Hwang SW, Choung HK, Lee YJ, Khwarg SI. Lacrimal silicone intubation for anatomically successful but functionally failed external dacryocystorhinostomy. Korean J Ophthalmol. 2007 Jun;21(2):70-3. PMID: 1759223525

[7] Bartley GB. Lacrimal intubation during dacryocystorhinostomy. Am J Ophthalmol. 1988; $106: 635$

[8] Anderson RL, Edwards JJ. Indications, Complications, and Results with silicone stents. Ophthalmology. 1979 Aug;86(8):1474-87. PMID: 542249

[9] Kim SE, Lee SJ, Lee SY. Clinical significance of microbial growth on the surface of silicone tubes removed from dacrocystorhinostomy patients. Am J Ophthalmol. 2012 Feb;153(2):253-257.e1.

\section{Volume 4 Issue 12, December 2015}




\section{International Journal of Science and Research (IJSR) \\ ISSN (Online): 2319-7064}

Index Copernicus Value (2013): 6.14 | Impact Factor (2014): 5.611

[10] Vieira GS, Xavier ME. Results and complications of bicanalicular intubation in external dacryocystorhinostomy. Arq Bras Oftalmol. 2008;71(4):529-33.

[11] Coban DT, Beden U, Sonmez B, Erkan D. Outcomes of external dacryocystorhinostomy and effects of the incision type on cosmetic and functional outcomes. $\mathrm{J}$ Clin Anal Med. 2011;2(1):21-4

[12] Anderson RL, Edwards JJ. Indications, complications and results with silicone stents. Ophthalmology 1979;86(8):1474-87

[13] Ozay S, Bakbak B, Onder F. [Silicone tube indications, external dacryocystorhinostomy]. MN Oftalmoloji 2005; 12:152-5

[14] Bayhan SA, Recep ÖF, Düzen B, Hasıripi H [The results of external dacryocystorhinostomy operations performed with single flap and double flaps]. T Oft Gaz. 2008;38:371-4

[15] Choung HK, Khwarg SI. Selective non-intubation of a silicone tube in external dacryocystorhinostomy. ActaOphthalmolScand 2007;85(3):329-32.

[16] Madge SN, Selva D. Intubation in routine dacryocystorhinostomy: why we do what we do. Clin Experiment Ophthalmol 2009; 37(6): 620-3.

[17] Saiju R, Morse LJ, Weinberg D, Shrestha MK, Ruit S. Prospective randomised comparison of external dacryocystorhinostomy with and without silicone intubation. Br J Ophthalmol. 2009;93(9):1220-2.

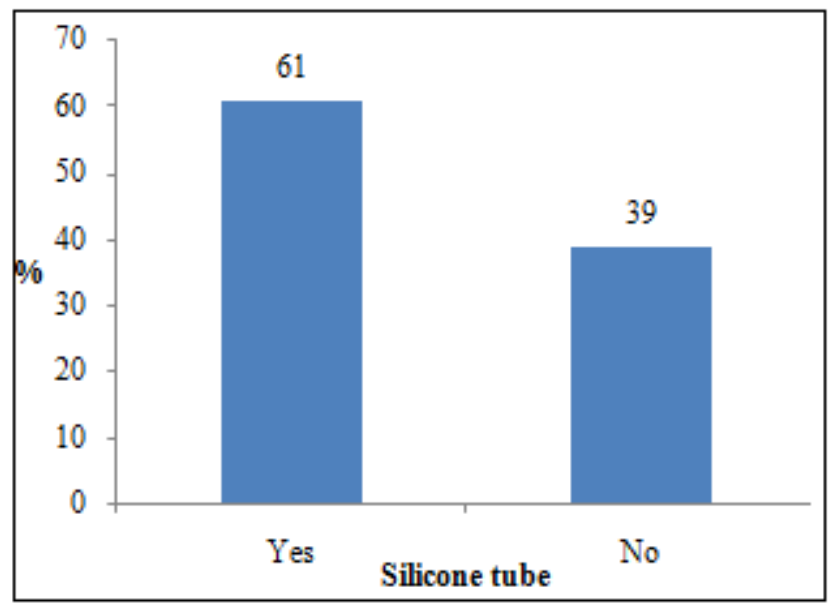

Figure 1: The frequency use of silicone tube

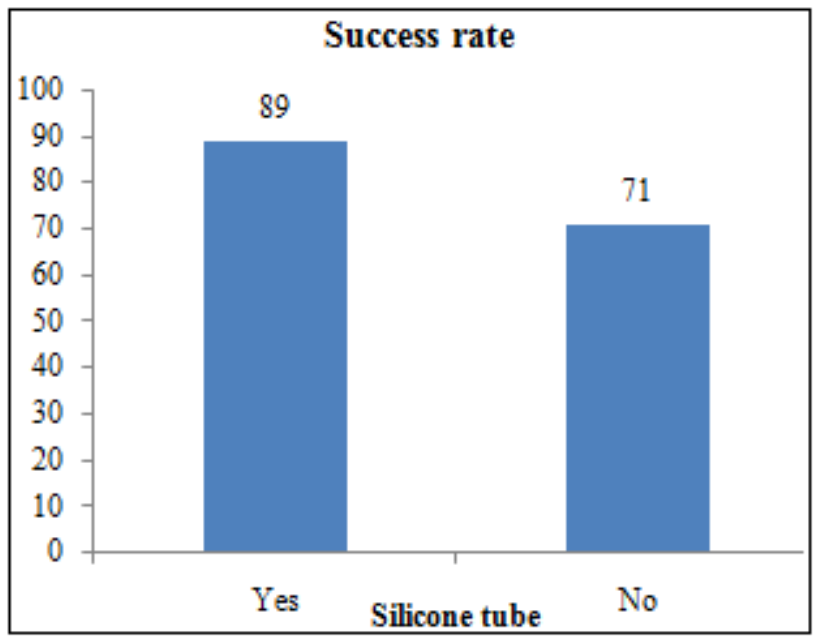

Figure 2: The success rate

Volume 4 Issue 12, December 2015 